\title{
Regional Mobility in Europe: The Importance of CEEPUS Based on Hungarian Evidence
}

\author{
Peter Holicza
}

\section{Introduction}

The CEEPUS program is currently in its third phase since it was launched in 1993. The program was initiated in Austria, and the founding contract was signed in Hungary. At that time, there were only 6 countries participating: Austria, Bulgaria, Hungary, Poland, Slovakia and Slovenia. Today, 16 countries participate in CEEPUS as beneficiaries of institutional networking, professional projects and inter-institutional mobility, joint research and degree programs (CEEPUS 2019). The program is based on networks established by faculties or departments of higher education institutions. The network has one coordinator, and the other institutions are partners. Several institutions from one country can participate in the same cooperation-but at least three institutions from three countries are required to form a network. These networks are thematic collaborations focusing on a specific professional topic of their choice - for example, a discipline-focused or interdisciplinary approach, joint training, joint research, publications (Scheck et al. 2015). In the first phase (1995 to 2004), the focus was on cooperation and recognition contributing to the formation of the European Higher Education Area, while the next two phases (2005 to 2010 and 2011 to 2019- present) aimed to focus on content development beyond partnerships. In the academic year 2005/2006, the program supported 35 professional networks and that number increased to 80 by $2019 / 2020$. Of the number of coordinated networks that were selected for support over the last 15 years, Austria (174), Poland (113) and Romania (109) are having the most. Hungary ranks 5th in this list with a total of 90 coordinated projects. With regard to mobility, until the current academic year, 24,940 student mobilities have been completed (Schuch 2019). However, there are notable differences among countries by the sending and receiving rates. Austria and Slovenia tend to be receiving countries, while Serbia, Croatia and Poland tend to send most of the students and professors abroad. In the Hungarian case, the ratio is nearly balanced (TPF 2019a).

\footnotetext{
P. Holicza ( $\square)$

Óbuda University, Budapest, Hungary

e-mail: holicza.peter@rh.uni-obuda.hu 
In addition to student mobility, the CEEPUS also supports study visits for 20,010 during the same period. In addition, there are 6,500 so-called free-movers, i.e. mobilities between higher education institutions in CEEPUS countries, independently of their networks (TPF 2019a).

Beyond mobility numbers, the program places a strong emphasis on quality and long-term achievements as well. The CEEPUS Ministers' Prize was established in 2001 to recognize the best performing networks. It has been awarded annually since 2002-Hungary won 8 times, Austria 4, Romania 3, Poland 2, Slovakia and Slovenia 1 time-based on their excellency, being operational for at least 3 years, utilization rate and well-allocated resources (Schuch 2019).

\section{CEEPUS in Hungary}

The program was coordinated by the Ministry of Education until 1997 when the Hungarian CEEPUS Office was established within the Tempus Public Foundation. As a partner, the Ministry of Education provides the financial support for the program each year. According to Hungarian CEEPUS Office data, the utilization of the incoming quotas (the program finances the incomers and the amount of support is defined by mobility months) draws a positive and progressing picture. Assuming the rates of Fig. 1 below, the CEEPUS program is very efficient in utilizing the available domestic funds, with minimal residual funds. There is little difference between the available and the used quotas: the lowest utilization rate was $88 \% 10$ years ago compared to $96 \%$ in recent years (TPF 2019a).

An important feature of the program is that the scholarship for incoming participants is provided by the host country. Its amount varies from country to country, Hungary is among the highest contributors (4th) for Bachelor, Master and $\mathrm{PhD}$ students. Pro-

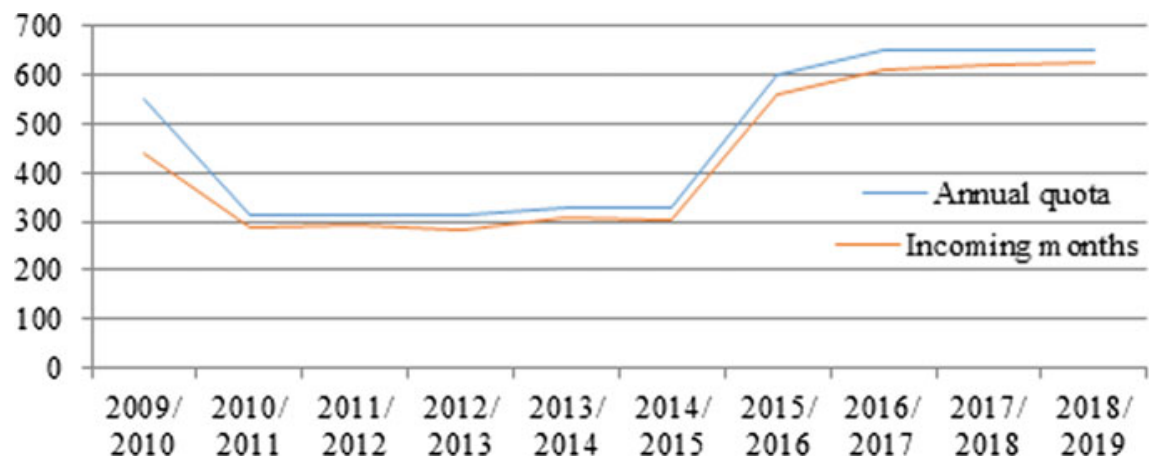

Fig. 1 Utilization of Hungarian CEEPUS quotas (months) Source Hungarian CEEPUS Office data 
fessors are usually given higher grants; Hungary is in the middle position on this scale (8th place).

In terms of the number of networks, a constant increase can be observed. Hungarian participation is relatively high, though not constant-between 53 and 62 in recent years. In contrast, the number of Hungarian-led networks is not increasing-apart from a few years when it reached 9. There are currently 4-5 Hungarian-coordinated networks. In other words, Hungarians are more likely to be partners in a network (Uszkai and Dános 2014).

Including free-mover mobilities, 26 (approx. 40\%) of the Hungarian higher education institutions (HEI) are involved, this number has not increased significantly in recent years. In contrast, the vast majority is active in the Erasmus+ program: 45-50 institutions apply for mobility grants each year. Considering the number of faculties and departments participating in CEEPUS, the growth is more evident as it increased from 24 (in 2005-2006) to 120 that it currently counts (TPF 2019a).

\subsection{Incoming Mobility}

Based on the data provided by the Hungarian CEEPUS Office, during the last 10 years (2009/10 to 2018/19), most of the students came from Romania, Poland and Slovakia-Erasmus+ Program Countries-followed by Serbia as Partner Country (since 2019, Serbia is Program Country as well). Focusing on the Partner Countries, a significant increase is visible mostly on the arrivals from Kosovo, Montenegro and North Macedonia (TPF 2019a).

The number of participants increased evidently in 2015 when the quota almost doubled compared to the previous year. The number of incoming professors and the number of funded short-term student mobility months increased, while the length of long-term student mobilities did not increase significantly. In other words, one of the attractive features of the CEEPUS program is the flexibility in terms of duration: it is not mandatory to spend a full semester at the partner university, shorter study periods are an option as well. The average length of stay is nearly the same for the short-term students and teaching staff_-nearly 1 month, while the long-term student mobility varies between 4-5 months. The trend of teaching staff mobility to Hungary is in line with the program level, where the involvement of professors and senior researchers is increasing, approaching the student mobility numbers (Schuch 2019).

\subsection{Outgoing Mobility}

There are fewer statistics available on outgoing mobility, as in the CEEPUS program, the host country finances the stay. Therefore, the number of students and professors can be indicative instead of the financed months spent abroad. Similarly 
to the incoming mobility, there has been a shift towards teaching staff mobility over the last 10 years with fewer students travelling for long term mobilities.

The target countries of students and professors are significantly different. While a quarter of professors chose Romanian institutions, more than a third of students travelled to Austria. The second most popular teaching destination is Slovakia, where $20 \%$ of the professors travel to. As for the students, Poland is the second favourite option. Looking at the institutions, most of the students target the University of Vienna, the Babes-Bolyai University and the University of Ljubljana; while most of the professors tend to visit Technical University of Cluj-Napoca, Babes-Bolyai University and thirdly the Technical University of Kosice (TPF 2019a).

Comparing the numbers, it is evident that Austria is a very popular destination for Hungarian students (675), but only a small part (89) of Austrian students went to Hungary. This ratio is balanced with Poland, where the Polish student participants account for (279), and the Hungarians for 300 .

Most of the visiting professors arrive from Romania, Slovakia, Serbia and Poland. The Western-Balkan States show relatively low, but increasing statistics. The CEEPUS participation did not suffer any decrease in mobility numbers when these countries became Erasmus+ Partner Countries (TPF 2019a).

\section{The Effects of CEEPUS in Hungary}

Below, the survey and focus groups interview results are presented and elaborated on. As part of this evaluation study, a survey has been designed and delivered to 114 Hungarian network coordinators in September, 2019. Besides the demographic variables, it included 18 multiple-choice, 5-point Likert-scale and open-end questions overall to better understand the effects of the program, future implications and possibilities for improvement. Out of the total sample, 41 responds are considered complete and are included in the analysis. This sample represents 22 different universities and colleges, where the respondents have at least 5 to 10 years of experience as coordinators, and the vast majority is highly experienced with up to 20 years in the program.

The results show that there are similar reasons for participants' motivation for student and professor mobility, regardless of the destination country. The number one factor of participation in CEEPUS is the shorter mobility options, second is the interest in the (professional) topic of the particular network, and thirdly the destination country. These features make the program the most attractive for participants (over other ones that do not have such features and do not provide such opportunities).

As a result of mobility, students' skills are enhanced equally towards expanded professional knowledge, improved language skills, intercultural competences and new relations. Professors mention firstly new relations thanks to CEEPUS participation, then getting to know the higher education system and good practices of other countries. Thirdly, they value the development of professional skills and intercultural 
competences. These results are in line with the international literature of CEEPUS mobility (Javorova 2013; Scheck et al. 2015; Welzer et al. 2017).

On Liker-scales, respondents evaluated the outcomes of CEEPUS, where the internationalization of Hungarian higher education was rated the most important contribution of the program. Secondly, its regional aspect is rather an advantage than disadvantage, as the program significantly contributes to international recognition of the Hungarian scientific sphere (publications, materials, references etc.) and facilitates professional collaboration among neighbouring countries and other member states in the CEE region. Considering the related achievements, first of all, the participants built trust, organized and realized short-term mobilities; and thirdly, begun to operate inter-institutional networks successfully.

The development, modernization of curricula, the creation of joint study materials and the issuance of joint diplomas received the least points on this scale. Administrative obstacles are likely to play a role in these low grades as well, however, it is important to mention that in half of the cases, the cooperation failed to contribute to significant achievements on the particular focus area. There is a lot to improve in the dissemination practices as well. Other than inner reports and summaries on the university webpages, the achievements do not get notable or significant visibility.

As the Central CEEPUS Office tries to analyze in-depth the possibilities of furthering the program to other education and research \& development areas (Horizon2020, Marie Curie, COST, Erasmus+), a related question was addressed in this survey as well. The answers were in line with the preliminary assumption that the above-mentioned programs, with the exception of Erasmus+, do not provide significant opportunities for Hungarian CEEPUS network members to further develop their results. Only three institutions indicated that the results are part of Horizon2020 projects, Marie Curie program was not referred by any institution, the COST program was cited once. The Visegrád Fund came up at three institutions, while domestic projects seem to be more relevant for sixteen of them. The results of the networks remained primarily within the institution which may also be influenced by the fact that the number of people working on the network from the Hungarian side was "less than five persons" (28). Six respondents indicated that they are working alone on the network at home, and only seven indicated a larger option with 6-10 people. This implies limitations and more difficult situation to step up from a small group size. These answers are in line with the official data of the National Agency, as most of the Hungarian networks have 6-10 partners.

For the program features to be improved, only two proposals received clear support from respondents: more dynamically growing monthly quotas (23) and providing further shorter mobility opportunities (23). No additional options were claimed by respondents even if the alignment with the focus area is not complete (see above). The definition of a new focus area is not supported (39). Similarly, the focus on innovation was rejected (36), involvement of new target groups is not supported either (25). It is notable that the focus group interview led to opposite results in some cases, such as inclusivity - the involvement of new target groups and the introduction of longer-term mobility opportunities. 
Without the continuation of the CEEPUS program (after 2025), most of the networks could keep working only partly (17), but 13 not at all, according to the survey. Only one institution could manage the same routines and practices without the program, while $10(25 \%)$ could not answer the question. The vast majority (30 of them) could not continue the short-term student mobilities, especially with the Balkan States - that is one of the most appreciated opportunities that CEEPUS provides. This puts in question the sustainability of the networks without CEEPUS support.

\subsection{Focus Group Interview Results-SWOT Analysis}

Based on the questionnaire, a focus group interview was conducted with the network and institutional coordinators of the participating universities. It focused on three main topics: preparing a SWOT analysis of the CEEPUS program, identifying the most popular characteristics - the unique selling point of the program (OPERA method employed), and finally collecting the good practices and added value of program participation on institutional or faculty level. As the participants overlapped with the questionnaire respondents, focus group discussions serve to refine, rather than to validate the results. Accordingly, the analysis led to the following observations.

The strengths of the CEEPUS program are:

- the variety of mobility and professional opportunities combined with flexible periods;

- its members having a common or similar historical and cultural background, therefore they understand each other easily;

- the regional character and geographical proximity, strengthening Central European linguistic relations;

- a diverse range of partners beyond EU countries;

- the free-mover option;

- the possibility to involve many partners, even external industrial ones (as Silent Partners);

- joint activities such as PhD co-supervision and training;

- the ease of application and administration: clear deadlines, easy cooperation with the office and the network.

Despite the special opportunities and positive experiences, several weaknesses have been mentioned:

- Coordinators dislike the annual requirement for application, which makes longerterm planning difficult and there is dissatisfaction in terms of the scholarship rates. In many countries, it is too low but often requires high administrative burdens. These administrative practices and rules vary from country to country-which are usually cumbersome and bureaucratic. 
- Payments are often delayed. In addition, the new system (new Traffic Sheet) makes it difficult to use.

- The application deadlines and administrative obligations are not well aligned with the typical schedule of higher education system (exam periods, breaks, summer break).

- There is no support for administrative tasks, therefore some of the coordinators are trying to "save money" elsewhere, unable to travel to meetings.

- Quota: network growth demand versus available quota. For larger and more effective networks, monthly quotas per institution are too low. If there is more than one partner from one country in a network, they will become competitors in some way.

- Compared to other programs: they are better known (e.g. Erasmus+) due to better promotion, higher scholarship rates and, in some cases, simpler administrative procedures.

- Some minimum quality requirements are missing: in the case of rejection of mobility applications, there is no explanation provided in some countries. The same network and action plan can be rejected in one year, while it received support in previous years.

The listed opportunities start with travel expenses provided, the introduction of staff mobility as a new target group, better branding, and making better use of the CEEPUS brand. In line with the missing feature above, a budget for organizational/administrative costs would be an uptake not only on the Hungarian but on international level as well (Schuch 2019).

Threats mentioned are different administrative requirements from country to country, dissatisfaction with the use of the new Traffic Sheet, bureaucratic burdens that originated from the annual application, more competitive rival programs such as Erasmus+ Credit Mobility and Campus Mundi.

\section{Summary}

Concluding the program features and experience of network coordinators, CEEPUS offers more and different kinds of opportunities for professional cooperation in the CEE and Western-Balkan Region than the Erasmus+ Program. The program is a good and more flexible starting point for a less experienced faculty, department, coordinator or student. It supports the internationalization of higher education institutions, in particular those not yet participating in Erasmus+ or Partner Countries. The thematic networks come from bottom-up initiatives and work on specific topics that they define and are specialized on. CEEPUS allows easier and more informal collaboration even with external partners such as industrial actors (Javorova 2013), which is unique among mobility programs. Networks are not necessarily linked to current national or international education policy priorities (e.g. innovation, STEM areas), but they highly contribute to the preservation of historical, cultural and linguistic heritage (Welzer et al. 2017), not to mention some of the shared principles with the 
Danube Strategy or the Visegrád Group (Vesković 2012; Zotti 2017). The regional aspect is mentioned several times on different platforms as a definite advantage of the program, especially for the non-EU countries where less international funds and scholarships are available.

For students, the "risk" of participating in CEEPUS is low-the shorter mobility periods are available and attractive on entry level or to the ones who are discouraged from staying abroad for a whole semester (at first). Credit recognition, administration problems and disadvantages in the home studies during the mobility are not common. The incoming mobility to Hungary is growing, the available quota was utilized at $96 \%$ in the last academic year. Most of the foreign students come from Romania and Poland; among Hungarian students, Austria is the most favourable, followed by Poland. Important to note that participation from the Western-Balkan States is increasing as well, the Erasmus+ International Credit Mobility did not affect it negatively (as pull factor) (Jovanovska et al. 2018; Schuch 2019).

Most of the Hungarian networks would suffer significant loss without CEEPUS in the future; only one institution would be ready to continue its network operations the same way. It is in line with the Croatian research results, where ca. 30\% of the coordinators would not be able to continue their current CEEPUS activities through other mobility programs or projects after 2025 . Approx. $60 \%$ of them stated that only to a smaller extent or partly they could keep up their related activities. Due to these facts and the Hungarian achievements in the program, it is inevitable that CEEPUS is a change-maker in the region (TPF 2019b).

\section{Recommendations}

Along this 25 years of operation, the programme expanded and achieved a lot, but to keep it potential and attractive in the future, several improvements are needed. First of all, visibility and recognition to its special features that make it different from other mobility schemes (Jovanovska et al. 2018), especially the Erasmus+. Highlight and communicate the outstanding multilateral cooperation opportunities and relatively easy availability of non-EU state partnerships and mobilities. It is in line with the suggestions of the international impact study conducted by Scheck et al. (2015).

There is a strong demand for new, modern and user-friendly online platforms that begin with the main webpage of the program. Similarly to the Erasmus+, creative and attractive infographics would prove and promote the effects of CEEPUS mobility, especially in relation to those member states where the "big brother" is less present (yet).

As the coordinators suggest, financial support for administration as well as the involvement of staff mobility would be necessary and, at the same time, it would attract those institutions that are not participating in the programme. More inclusive strategy and targeted approach would enable the programme to keep up with high utilization of national quotas even when the competition is increasing with other mobility programs. The competitiveness would increase if the impressive participa- 
tion rates were supported with new (minimum) quality standards for more sustainable projects and effective program management.

As this research shows, in line with the international literature review (Scheck et al. 2019), the key of success is the flexibility and short-term mobility option, opportunities to organize and participate in summer universities, joint trainings, etc. that other programs do not support. In order to keep these strong pull-factors, the administrative burdens should not make any barriers in the host countries, where no common practices and program management standards are adopted. The number of monthly scholarships should be revised as well; participants aspire for higher rates-especially in the Balkan States, where it is the lowest currently. Considering the EU enlargement policy, it would be of great importance to increase their activities and involvement in the European higher education practices (Bošnjović and Trivun 2013; TPF 2019b). Concluding the role of CEEPUS, it is not an alternative program to Erasmus+ but complementary that allows for additional and different opportunities for regional collaboration.

Acknowledgements The conducted independent study was performed on the request of the Hungarian National Office-Tempus Public Foundation and the majority of the presented data was acquired from the same source.

\section{References}

Bošnjović, J., \& Trivun, V. (2013) Academic mobility in the Western Balkans. Business Systems Research, 4(1), pp. 76-86.

CEEPUS (2019). Central CEEPUS webpage, online: https://www.ceepus.info (10.11.2019)

Javorova, J. (2013) Conceptual Aspect of the CEEPUS Project "odern Trends in Education and Research on Mechanical Systems-Bridging Reliability, Quality and Tribology". Tribological Journal BULTRIB, (3), pp. 60-69.

Jovanovska et al. (2018) University Students' Views on the Impact of Student Mobility on their Achievements and Future Prospects. Journal of Contemporary Educational Studies/Sodobna Pedagogika, 69(2), pp. 132-143.

Scheck, H., Ivan, Z., \& Schuch, K. (2015) Evaluation CEEPUS III-Evaluation of CEEPUS'teacher mobility, Frequent travellers under the microscope. Project Report. Wien.

Schuch, K. (2019) The Uptake of European Programmes in the CEEPUS Cooperation Area, ZSICentre for Social Innovation

TPF (2019a) Tempus Public Foundation-Hungarian CEEPUS office data

TPF (2019b) CEEPUS: A közép-európai felsőoktatási csereprogram hatása a részt vevő magyar felsőoktatási intézményekben, p. 50.

Uszkai, A., \& Dános, Zs. (2014) Cross-border relationships of Central-European higher education institutions, 54th Congress of the European Regional Science Association: "Regional development \& globalization: Best practices"

Vesković, M. (2012) The Danube Macroregional Strategy and Good Practices Towards a Knowledge Society. Der Donauraum, 52(2), pp. 261-268.

Welzer et al. (2017) Cultural awareness in research and teaching, In Proceedings Cross-Cultural Business Conference 2017, pp. 289-296. Shaker Verlag.

Zotti, S. (2017) Academic Mobility in the Danube Region: The Need for New Multilateral Instruments, Mobility, Cooperation and the Danube Strategy. Der Donauraum, 57(1), pp. 77-83. 
Open Access This chapter is licensed under the terms of the Creative Commons Attribution 4.0 International License (http://creativecommons.org/licenses/by/4.0/), which permits use, sharing, adaptation, distribution and reproduction in any medium or format, as long as you give appropriate credit to the original author(s) and the source, provide a link to the Creative Commons license and indicate if changes were made.

The images or other third party material in this chapter are included in the chapter's Creative Commons license, unless indicated otherwise in a credit line to the material. If material is not included in the chapter's Creative Commons license and your intended use is not permitted by statutory regulation or exceeds the permitted use, you will need to obtain permission directly from the copyright holder.

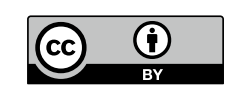

